Article

\title{
Control of Porosity in Parts Produced by a Direct Laser Melting Process
}

\author{
Tae Jun Jeon ${ }^{1}$, Tae Woo Hwang ${ }^{2}$, Hye Jeong Yun ${ }^{2}$, Chester J. VanTyne ${ }^{3}$ \\ and Young Hoon Moon ${ }^{2, *}$ \\ 1 Materials \& Production Engineering Research Institute, LG Electronics, Pyeongtaek, Gyeonggido 17709, Korea; \\ tjjeon@pusan.ac.kr \\ 2 School of Mechanical Engineering, Pusan National University, 30 Jangjeon-dong, Geumjeong-gu, \\ Busan 46241, Korea; twhwang@pusan.ac.kr (T.W.H.); hjyun77@pusan.ac.kr (H.J.Y.) \\ 3 Department of Metallurgical and Materials Engineering, Colorado School of Mines, Golden, CO 80401, USA; \\ cvantyne@mines.edu \\ * Correspondence: yhmoon@pusan.ac.kr; Tel.: +82-51-510-2372; Fax: +82-51-512-1722
}

Received: 27 November 2018; Accepted: 10 December 2018; Published: 11 December 2018

\begin{abstract}
Recent advances in direct laser melting (DLM) have demonstrated its great potential for manufacturing three-dimensional porous metal parts. Various combinations of powder layering and processing parameters can be set to adjust the porous properties of the final parts. This study presents the effects of powder morphologies and process parameters on porosity formation during DLM. Four types of Fe-powders composed of spherical or non-spherical particles with different sizes were experimentally investigated. Furthermore, the laser processing parameters, such as laser energy density, laser focus, and line spacing, which have a significant effect on the results, were characterized. In the case of a mixed powder composed of spherical and non-spherical powders, the packing density decreases as the non-spherical powder size increases. The porosity of the laser-melted layer increases with the degree of size misfit between the non-spherical and spherical powders. Decreased laser absorption and enlargement of the powder-depleted zone as a result of decreased packing density increases the porosity during DLM. The overall results show that the porosity of DLM parts could be actively controlled by adjusting the process parameters and powder morphologies.
\end{abstract}

Keywords: porosity; direct laser melting; mixed powder; densification; additive manufacturing

\section{Introduction}

Direct laser melting (DLM), also known as selective laser melting (SLM) or direct metal laser sintering (DMLS), is a rapid prototyping, 3D printing, or additive manufacturing (AM) technique designed to use a high power-density laser to melt and fuse metallic powders together. DLM has been widely used for net shape production, owing to its capacity to fabricate complex freeform geometries. The technology enables a wide spectrum of possibilities for constructing 3D parts for various applications such as automobiles, medical supplies, and mechanical parts. When compared with other traditional techniques, laser processing typically does not require mechanical toolings, and, therefore, exhibits high flexibility [1-5]. Porous metal parts have also been applied to filters, fluid-permeable components, electronic products, and biomaterials. As porous metal parts may be lightweight and exhibit high gas permeability and heat transfer capabilities, the development of functional products using porosity is very important in numerous industrial fields. However, it is challenging to control the porosity of porous metal parts precisely. Therefore, a quantitative analysis was performed in this study for the active control of porosity during DLM. Porosity is a common issue in laser-processed parts, and several studies have been performed on this topic. Porosity formation 
is a process-induced phenomenon that is strongly dependent on the processing conditions used to produce a part. It is generally believed that irregular-shaped pores are caused by inadequate fusion or melting [6]. Gong et al. [7] classified laser process windows according to the laser power and scan rate. Several process zones were identified, corresponding to incomplete melting, fully dense material, over-melting, and overheating. A statistical porosity evaluation was performed by using descriptors such as circularity, convexity, and elongation, which were related to the different process window zones. Qiu et al. [8] directly observed open pores on the top surfaces of laser-processed Ti-based alloy. The spherical pores were attributed to the incomplete re-melting of certain localized sites on the previous layer as well as the insufficient feeding of molten metal to these sites. Vilaro et al. [9] suggested that the spherical porosity formation in laser-processed Ti6Al4V alloy was a result of gas confinement during melting and rapid solidification. Li et al. [10] attributed porosity to poor flow, a lack of fusion, and incomplete re-melting of laser-processed 316L stainless steel under a relatively low energy input. Khairallah et al. [11] studied the porosity formation mechanism and pore defect generation using 316L stainless steel laser powder. Qiu et al. [12] determined that pore formation and the development of rough surfaces in Ti-6Al-4V alloy were strongly associated with unstable melt flow and splashing of molten material, based on results obtained from high-speed imaging and modeling. Panwisawas et al. [13] developed a melt flow dynamics model, and successfully used it to explain the morphological development of pores formed under different processing conditions. Razav et al. [14] investigated the effect of porosity on tensile behavior of Ti-6Al-4V specimens produced by laser engineered net shaping technology. They showed that the porous samples had considerably lower elongation at failure which was a result of stress raisers in the material, which facilitates the propagation of cracks in the sample. Razavi et al. [15] also investigated the fatigue behavior of porous Ti-6Al-4V parts produced by laser engineered net shaping technology. Although the static strength of porous samples and non-porous samples were almost identical, considerably lower fatigue strength was observed for porous samples because stress raising effect facilitates fatigue crack initiation and fatigue crack propagation along the net section of the sample.

As demonstrated, previous studies have mainly focused on porosity formation mechanisms and mechanical effects based on specific alloy systems. The size and morphology of powders must be strictly controlled due to their influence on packing behavior, material deposition, and subsequent laser consolidation. In the DLM, when the laser beam radiates towards the powder layer, laser beam energy is dissipated by means of absorption and scattering. In order to investigate the effect of powder size distributions on the scattering and absorption characteristics of the metal powder layer, ray tracing (RT) models have been proposed for modeling the interaction between laser radiation and powder particles more accurately $[16,17]$.

This study presents the effects of powder morphologies and process parameters on porosity formation during DLM. The effects of powder morphologies on porosity generation are analyzed by means of the scattering characteristics of test powders, while the effects of laser processing parameters are investigated using powder consolidation kinetics [18-20]. As DLM holds significant potential to become a robust technology, it is also critical to understand the complex physical phenomena taking place inside and around the melt pool, and how these may affect porosity generation. Furthermore, despite ongoing research efforts focusing on the characterization of porosity in the laser additive processes, practical studies on quantitative porosity control have not been sufficiently represented and are generally lacking. Therefore, this quantitative study may provide a basis for active porosity control in laser processing. To this end, functionally-graded parts with variable porosity densities were fabricated to demonstrate the active porosity control during the DLM process. 


\section{Experimental Procedures}

\subsection{Laser System}

Figure 1 provides a schematic of the DLM system. The laser system source is an YLR-200 fiber laser (IPG, Nordrhein-Westfalen, Germany), with a maximum output laser power of $200 \mathrm{~W}$, wavelength of $1.07 \mu \mathrm{m}$, and laser beam diameter of $0.08 \mathrm{~mm}$ in the focal position. The powder layering thickness was precisely controlled by a build platform that can be moved with a resolution of $10 \mu \mathrm{m}$. A scanner (SCANLAB hurrySCAN 20, Munich, Germany) was used to control the laser emission. In order to prevent oxidation, argon shielding was applied during the laser melting process. During the DLM procedure, a thin powder layer is firstly applied to the substrate using a layering bar. Secondly, the metallic powder is melted by a scanning laser beam and it adheres to a base substrate or previously-solidified metallic layer below the top layer. Finally, the build platform is lowered by one powder layer thickness to prepare for the following powder layering and maintain the surface in the focal plane. By repeating this procedure, 3D parts with a target shape are fabricated. In order to investigate the effect of defocusing distance on porosity formation, the focal plane has been changed, as illustrated in Figure 2.

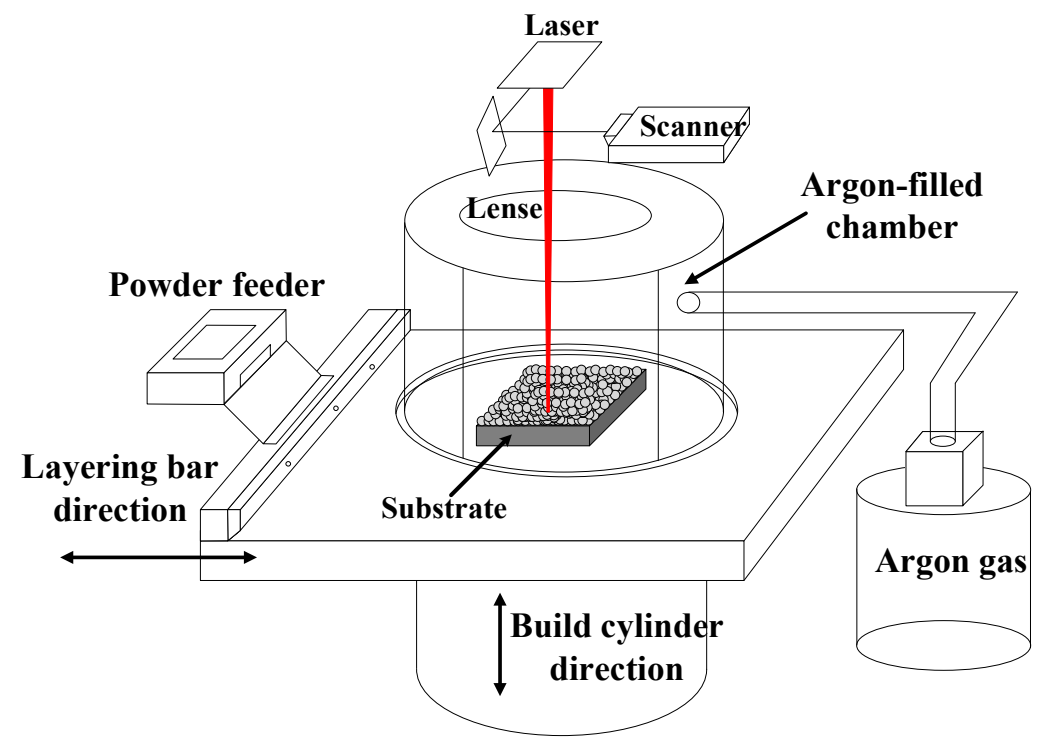

Figure 1. Schematic of DLM system.

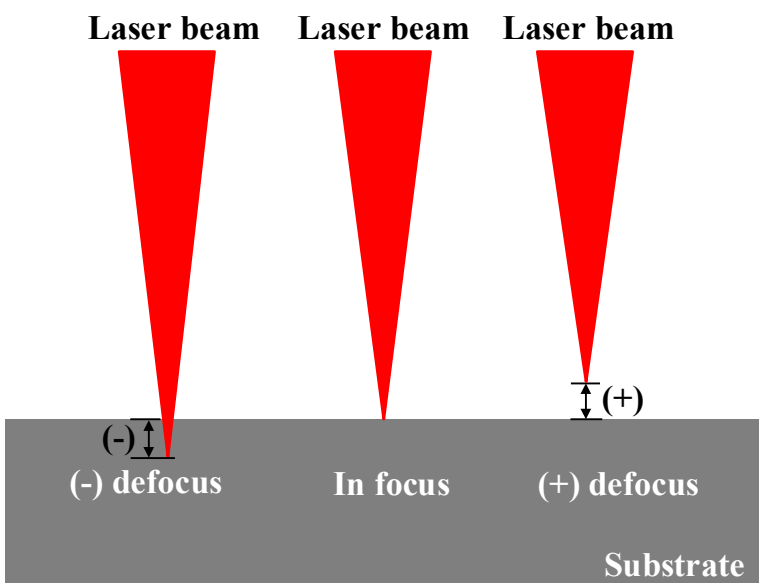

Figure 2. Schematic of defocusing distance in DLM system. 


\subsection{Materials}

Commercially-available Fe-powders (HKKSolution, Seoul, Korea) were used in the experiment, and their morphologies are illustrated in Figure 3. The powder size distribution and morphology influence the physical properties of the parts created. The particle size was classified by the sieve mesh size, using a Ro-Tap Sieve Shaker (HJ-2152). A laser diffraction particle size analyzer (LS ${ }^{\text {TM }} 13320$ SW) was used to measure the particle size distribution. This device analyzes the particle sizes by dispersing the particles in an appropriate solvent and using laser scattering. The Gaussian-like particle size distributions are illustrated in Figure 4, while Figure 5 indicates the approximate major/minor axis ratio of the non-spherical powder. The average ratio was estimated to be approximately 1.6, regardless of particle size, and AISI D2 was used as a base plate.

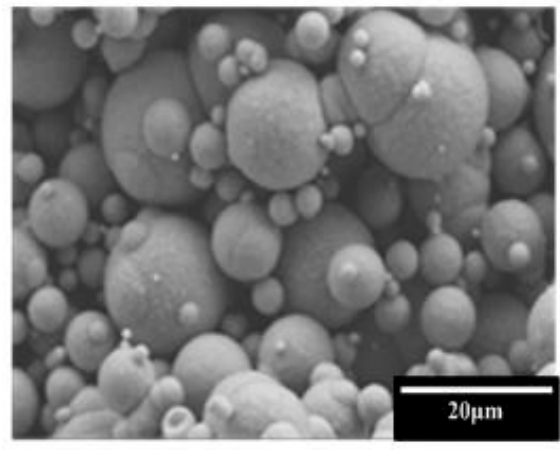

(a)

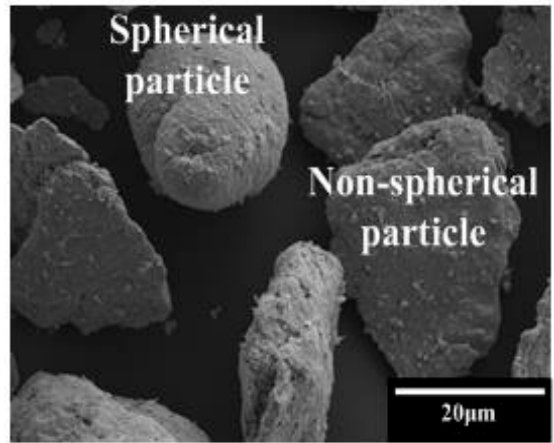

(b)

Figure 3. Powder morphology: (a) spherical and (b) mixed powder with non-spherical particles.

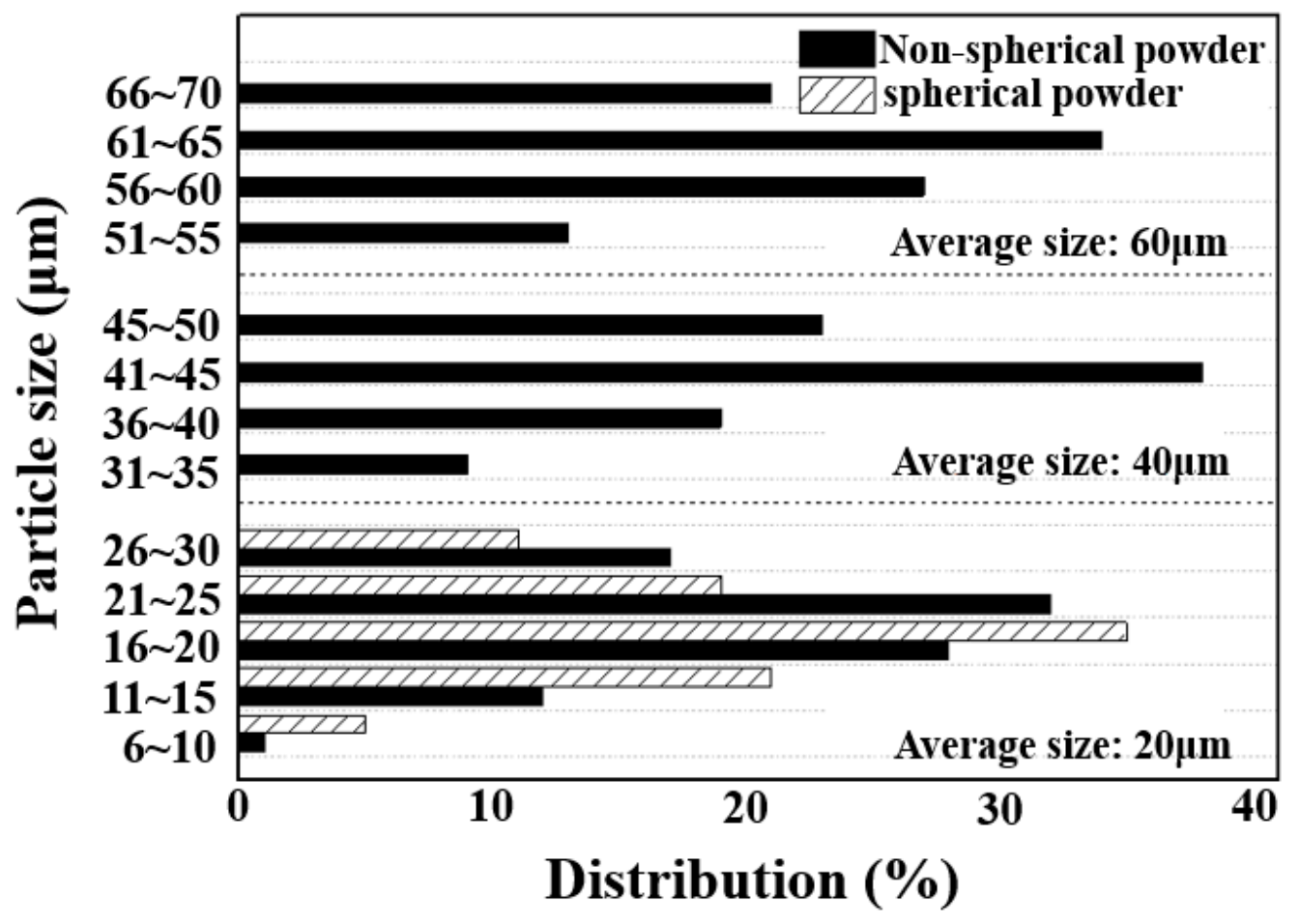

Figure 4. Particle size distributions of test powders. 


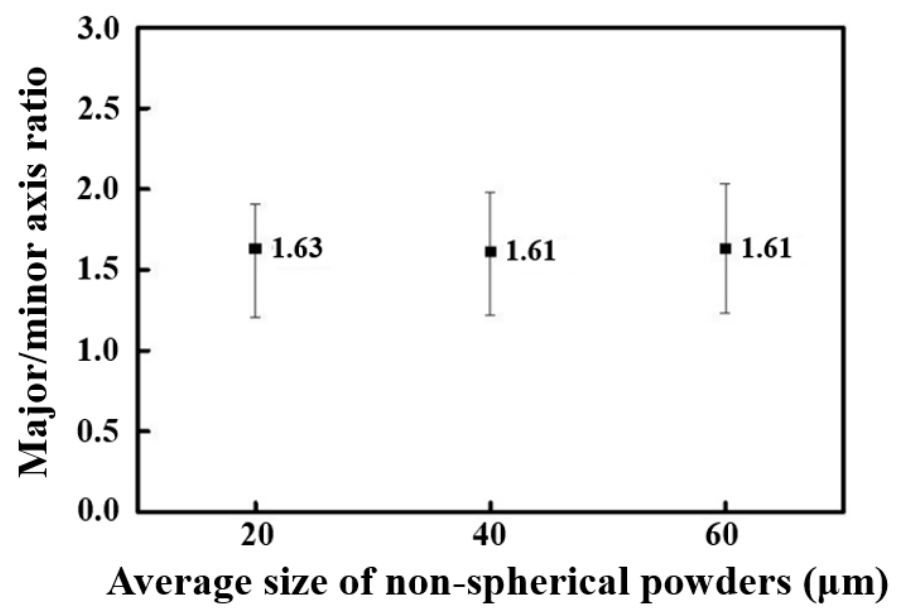

Figure 5. Major/minor axis ratio of non-spherical powders.

Four types of powders were investigated for this analysis. Powder 1 was composed of fully spherical powder with an average particle size of $20 \mu \mathrm{m}$. Powders 2, 3, and 4 were mixed powders composed of $50 \%$ spherical powder with an average particle size of $20 \mu \mathrm{m}$ and $50 \%$ non-spherical powder with average particle sizes of $20 \mu \mathrm{m}, 40 \mu \mathrm{m}$, and $60 \mu \mathrm{m}$, respectively. The powder characteristics are shown in Table 1.

Table 1. Classification of test powders.

\begin{tabular}{lcc}
\hline & $\begin{array}{c}\text { Size of Spherical Powder } \\
\text { (Mixing wt \%) }\end{array}$ & $\begin{array}{c}\text { Size of Non-Spherical Powder } \\
\text { (Mixing wt \%) }\end{array}$ \\
\hline Powder 1 & $20 \mu \mathrm{m}(100 \%)$ & - \\
Powder 2 & $20 \mu \mathrm{m}(50 \%)$ & $20 \mu \mathrm{m}(50 \%)$ \\
Powder 3 & $20 \mu \mathrm{m}(50 \%)$ & $40 \mu \mathrm{m}(50 \%)$ \\
Powder 4 & $20 \mu \mathrm{m}(50 \%)$ & $60 \mu \mathrm{m}(50 \%)$ \\
\hline
\end{tabular}

Figure 6 illustrates the initial stacked height after packing the same weight of non-spherical and spherical powders. The powder packaging density decreases with an increasing non-spherical powder size, while the stacked height increases. The measured apparent densities for powders $1,2,3$, and 4 were $2.46 \mathrm{~g} / \mathrm{mm}^{3}, 2.40 \mathrm{~g} / \mathrm{mm}^{3}, 2.35 \mathrm{~g} / \mathrm{mm}^{3}$, and $2.31 \mathrm{~g} / \mathrm{mm}^{3}$, respectively. The apparent density decreases with the size misfit degree between the non-spherical and spherical powders.

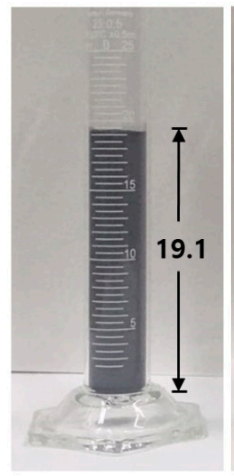

(a)

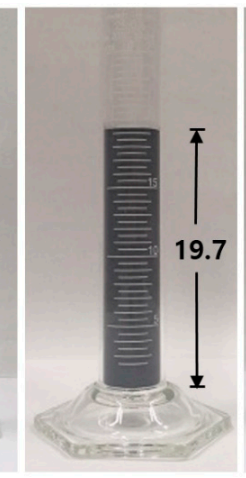

(b)

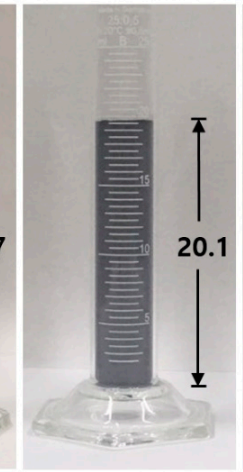

(c)

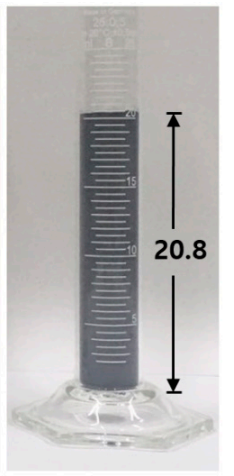

(d)

Figure 6. Initial stacked height of: (a) powder 1, (b) powder 2, (c) powder 3, and (d) powder 4.

\subsection{Porosity Analysis}

The porosity of DLM parts can be measured by several methods [21,22]. In this study, the plane porosity based on 2D image analysis is used as a quantitative porosity index. Usually, plane porosity is equal 
to the bulk porosity if the macroscopic structure is homogeneous. Microscopic observations were performed using an optical microscope (OLYMPUS GX-51) and the image analysis software TDI Plus 5.0. An image obtained by enlarging a cross-section of the test piece at $100 \times$ magnification was analyzed. The microscope image was binarized in order to obtain plane porosity, as illustrated in Figure 7.

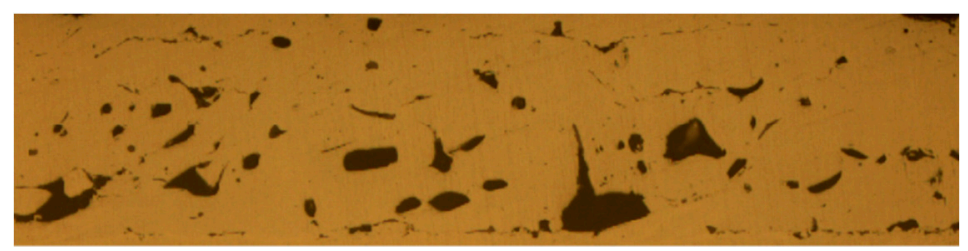

(a)

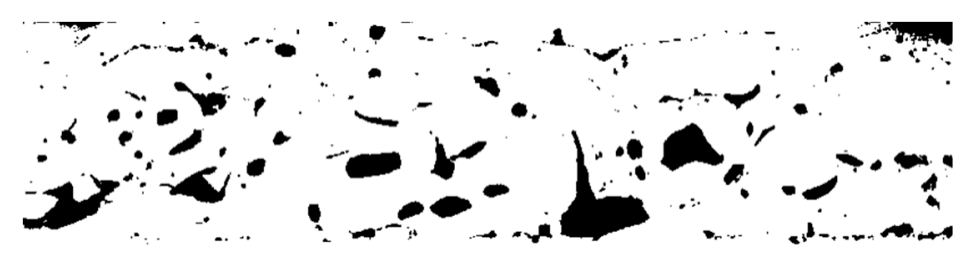

(b)

Figure 7. Cross-sectional microscopic view of powder 3: (a) image obtained from optical microscope and (b) image following binarization process.

\section{Results and Discussion}

\subsection{Characteristics of Single-Track Melting Test}

The soundness of a fabricated part depends on the characteristics of the melting and solidification of metallic powder. This soundness can be observed directly in a single-track melting test, as shown in Figure 8. Full melting of the powder bed and formation of a continuous fused metal line was achieved by means of a single track-melting test.

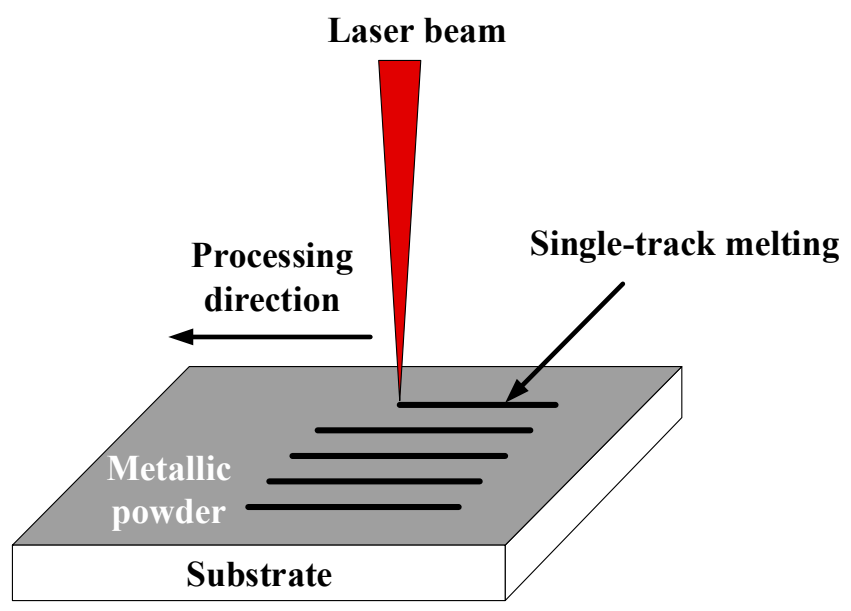

Figure 8. Schematic of single-track melting.

Single-track melting was performed using laser powers of 150 and $200 \mathrm{~W}$, scan rates of 36.6 to $220 \mathrm{~mm} / \mathrm{s}$, and a hatching distance of $0.06 \mathrm{~mm}$. The depths and widths of the bead produced by various process parameters were measured using an image analysis program. In general, a height/width ratio of approximately 0.5 is considered to be optimal for the bead shape [23]. Figure 9 illustrates the bead shapes of powders 1 and 2 at different scan speeds. The bead size decreased with an increasing scan rate, owing to the reduced heat input. 


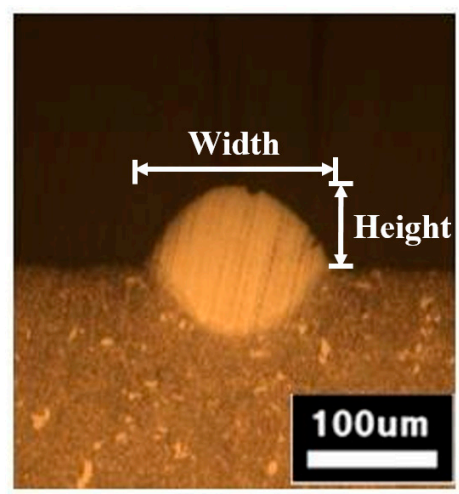

(a)

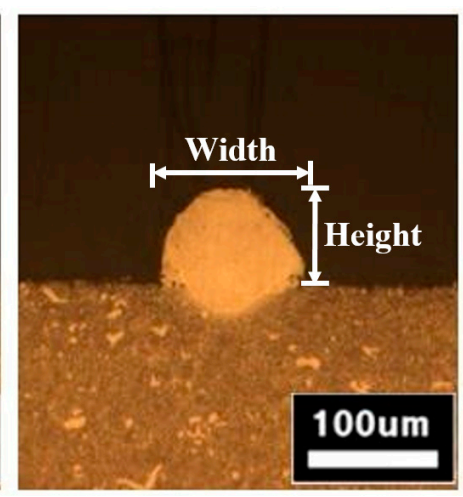

(b)

Figure 9. Cross-sectional views of single-track beads processed at different scan rates: (a) powder 1 and $(\mathbf{b})$ powder 2.

Figure 10 shows the height/width ratio of a single-track bead with an increasing scan rate for powders 1 and 2. The optimum bead shapes for powders 1 and 2 were obtained at laser scan rates of $110 \mathrm{~mm} / \mathrm{s}$ and $73 \mathrm{~mm} / \mathrm{s}$, respectively. This difference in scan rates means that the powder morphology significantly affects the bead shape in DLM, which agrees with the results of Simchi [24]. The differences in powder packing density, heat conduction, laser diffraction, and layering height are considered to be the main causes of the varying behaviors for powders 1 and 2 .

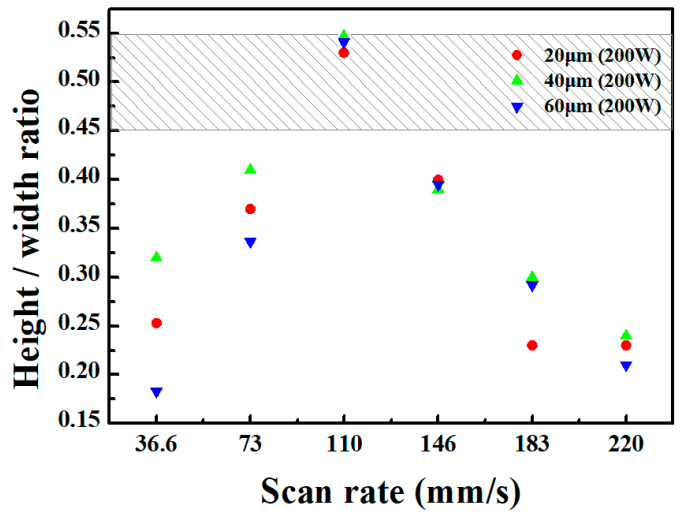

(a)

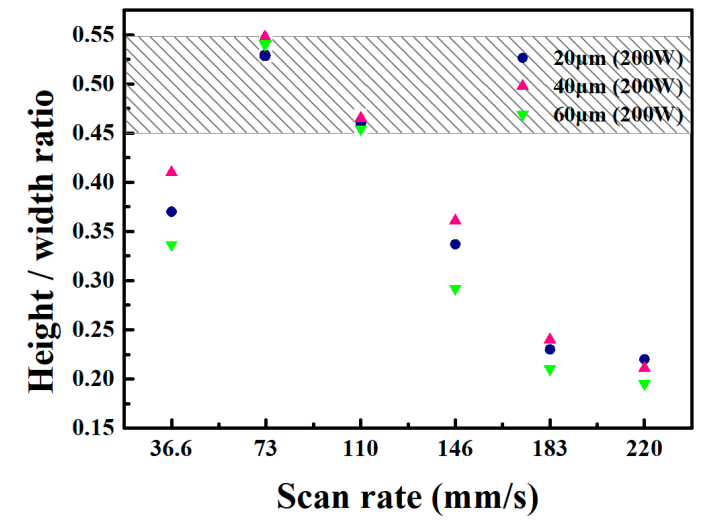

(b)

Figure 10. H/W ratio of single-track bead: (a) powder 1 and (b) powder 2.

\subsection{Porosity in Multi-Track DLM Process}

In order to investigate the porosity generated during the DLM process, a quadrangle structure was fabricated by means of a multi-track melting test. The multi-track melting test was performed at a laser power of $200 \mathrm{~W}$, scan rate of $110 \mathrm{~mm} / \mathrm{s}$, and line spacing of $0.06 \mathrm{~mm}$. As illustrated in Figure 11, the cross-hatching technique was applied in the laser scanning pattern in order to fabricate the quadrangle structure. The fill pattern was rotated by $90^{\circ}$ when scanning the subsequent layer to reduce the impedimental effect of a larger uneven layer produced during the previous scanning process. 


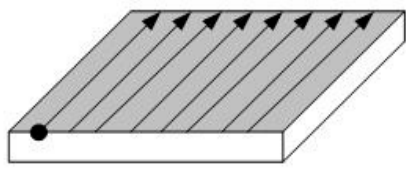

$1^{\text {st }}$ Layer $\left(0^{\circ}\right)$

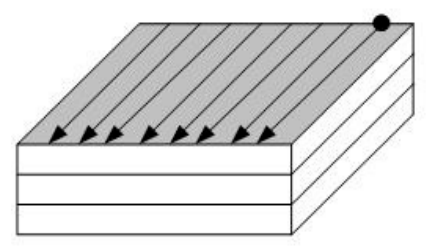

$3^{\text {rd }}$ Layer $\left(180^{\circ}\right)$
- Starting point

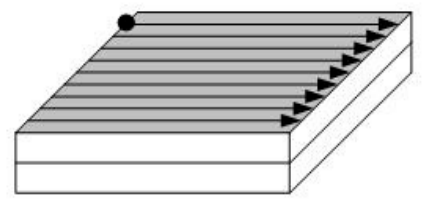

$2^{\text {nd }}$ Layer $\left(90^{\circ}\right)$

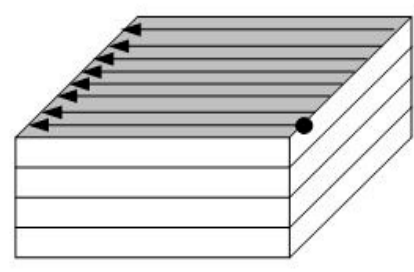

$4^{\text {th }}$ Layer $\left(270^{\circ}\right)$

Figure 11. Fabrication of quadrangle structure by cross-hatching technique.

The effects of processing parameters on porosity generation were investigated, including scan rate, layering thickness, line spacing, and powder size. Figure 12 shows cross-sectional views obtained from the multi-track test. The powder layering thickness was adjusted based on the DLM operational stability. The layering thicknesses of powders $1,2,3$, and 4 were $0.03 \mathrm{~mm}, 0.03 \mathrm{~mm}, 0.06 \mathrm{~mm}$, and $0.09 \mathrm{~mm}$, respectively.

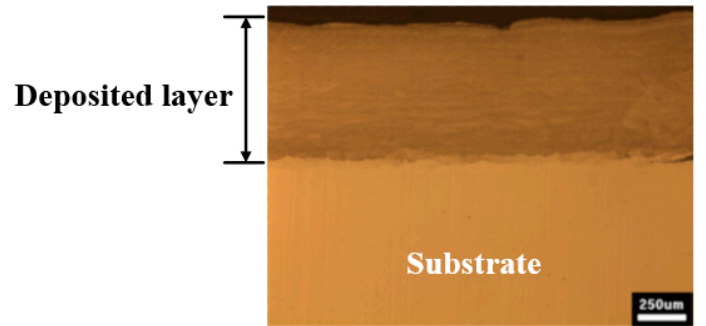

(a)

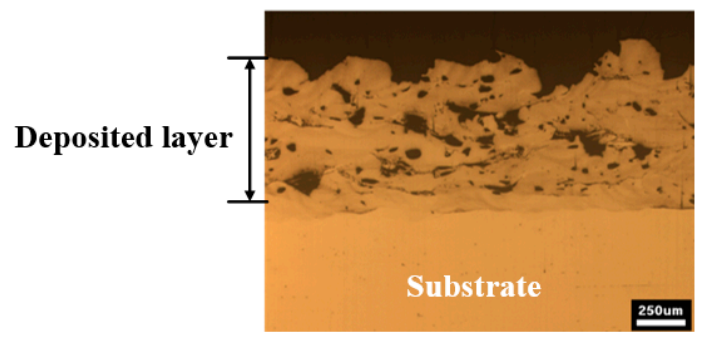

(c)

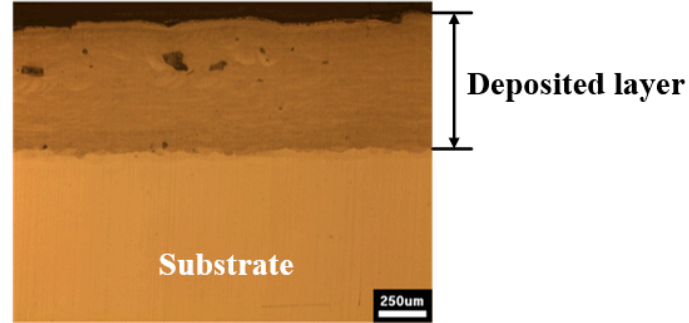

(b)

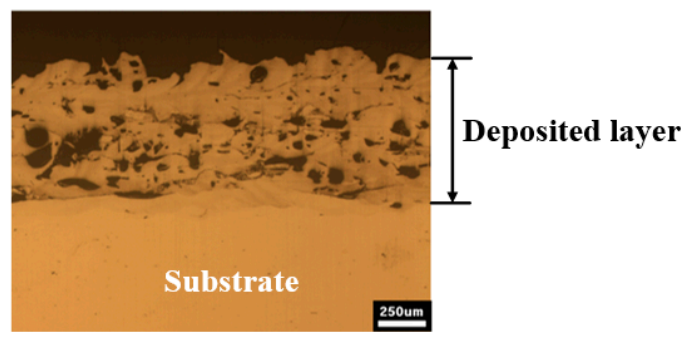

(d)

Figure 12. Porosities in deposited layers obtained using: (a) powder 1, (b) powder 2, (c) powder 3, and (d) powder 4 .

As illustrated in the figure, the porosity varies significantly according to the powder size and morphology. In the case of powder 1 , a fully dense layer without porosity was obtained. In the case of deposited layers using powders 2,3 , and 4 , the porosity increased with the size of the non-spherical powder mixed with the spherical powder. The variation in porosity densities is mainly caused by the powder packing density [25]. When larger powders with non-spherical morphologies are mixed with spherical powder, numerous pores are generated as a result of the reduced powder packing density. 
Laser radiation penetrates into the powder through the pores, to a depth of several particle diameters, because of multiple reflections. If sufficient laser radiation is applied, the powder particles begin to coalesce and the powder layer structure changes, which has a considerable impact on the effective radiative and thermal properties and thereby influences the radiation, heat transfer, and consolidation kinetics [26].

When the laser beam radiates towards the powder layer, laser beam energy is dissipated by means of absorption and scattering. Part of the laser energy is absorbed by the powder particles and substrate, while the remaining energy is scattered back from both. Therefore, understanding the interaction between the powder and laser beam is key to laser penetration and powder bed absorption. The RT simulation indicated that metal powder layers with higher packing density exhibit increased absorptivity, owing to multiple reflections of laser radiation between powder particles. As illustrated in Figure 13, the laser beam is taken as the ray penetrating into the powder bed, which is reflected and absorbed by the powders. This illustration was based on a simulation of three rays. The metal layer was divided into six layers and the total absorption points were added. For example, referring to Figure 13a, in the first sub-layer, there are six absorption points. Having calculated the absorption points in each sub-layer, the total absorption points of each layer can be obtained [16]. Assuming that the absorbed energy at each absorption point is the same for the sake of simplicity, the number of absorption points can provide an index of energy absorption at each layer. As the number of total absorption points for powders 1, 2, 3, and 4 are 53, 42, 34, and 28, respectively, less energy is absorbed with increasing powder numbers. Therefore, powder 1 exhibits a dense layer, while powder 4 exhibits the most porous layer.

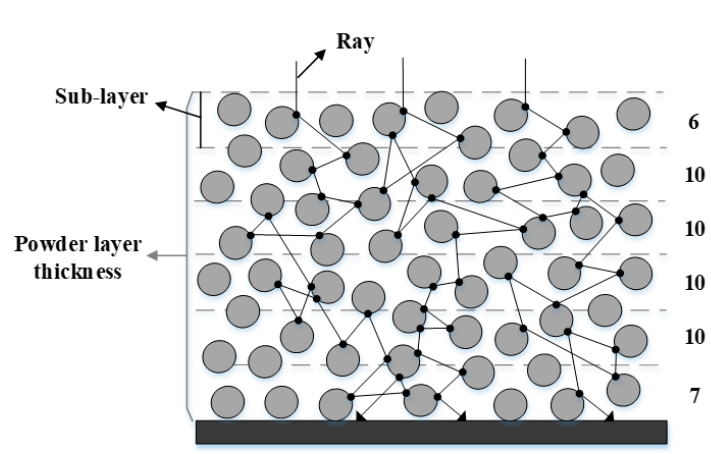

(a)

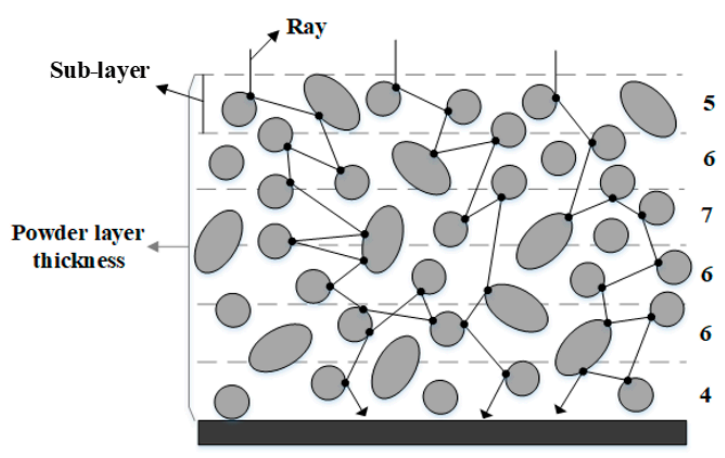

(c)

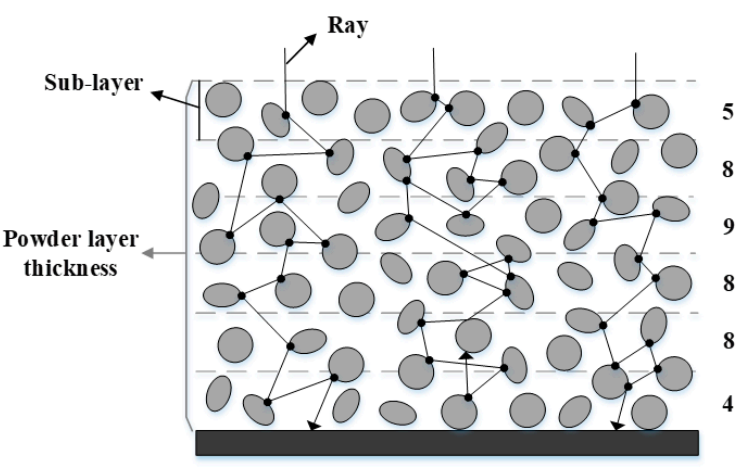

(b)

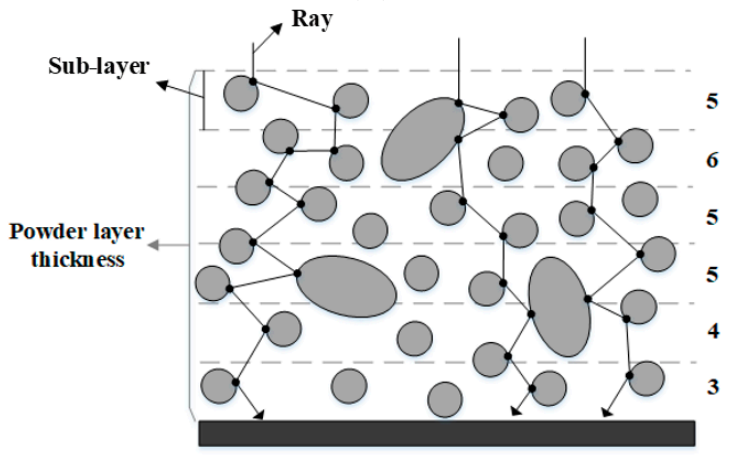

(d)

Figure 13. Illustration of RT model: (a) powder 1, (b) powder 2, (c) powder 3, and (d) powder 4.

The effect of different amounts of laser power on porosity was investigated using a laser scanning speed of $110 \mathrm{~mm} / \mathrm{s}$ and line spacing of $0.06 \mathrm{~mm}$. Figure 14 shows cross-sectional views obtained from the multi-track test using different test powders. In the case of powders 3 and 4, $100 \mathrm{~W}$ laser power leads to unstable deposition, owing to insufficient heat input. 


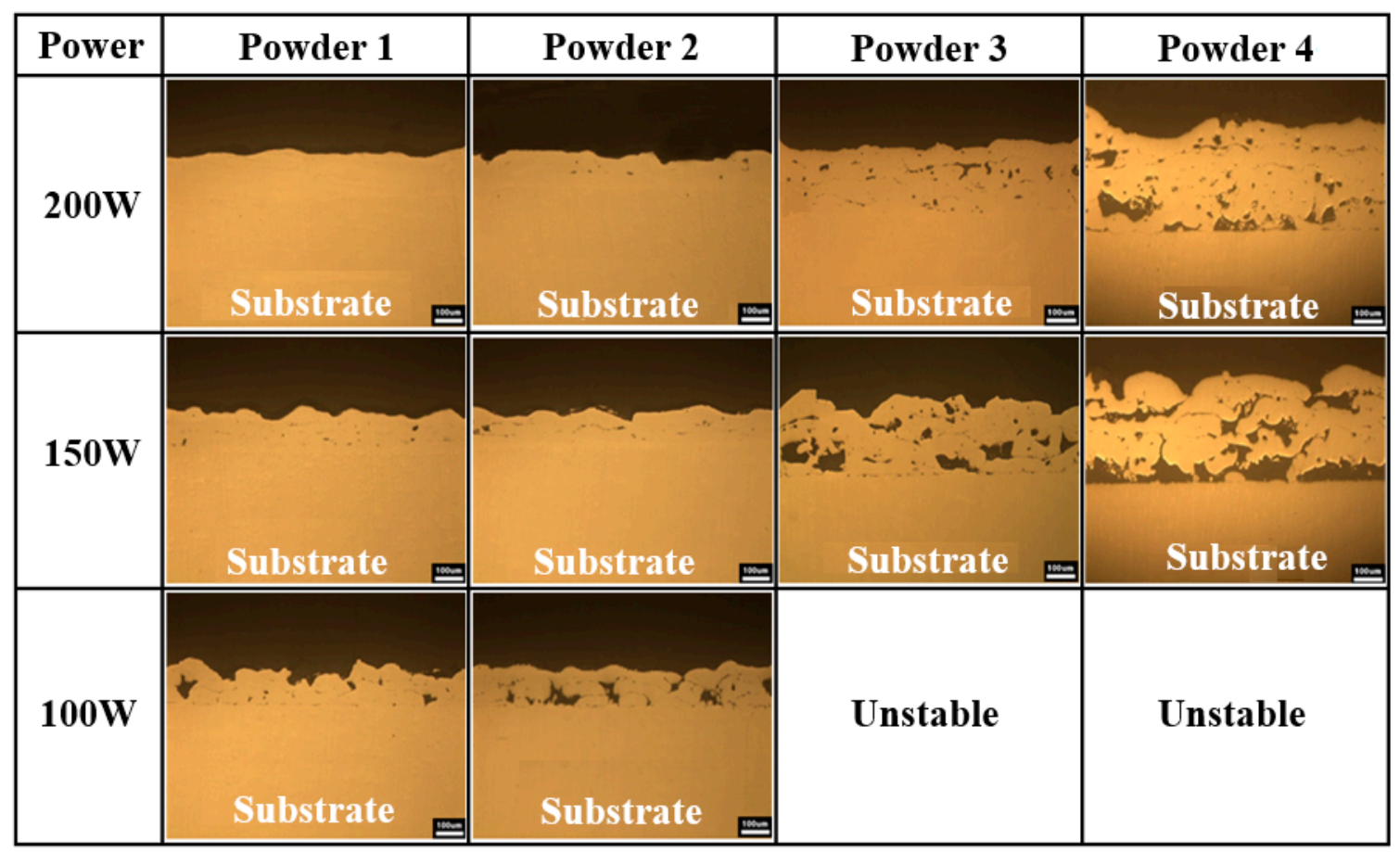

Figure 14. Porosities in deposited layers processed using different laser powers.

A relation between the apparent density of the respective powders and the porosity of the molten layers are shown in Figure 15. As shown in the figure, higher porosity has been obtained with decreasing apparent density. The porosity decreases with increasing laser power, and the porosity of the respective powders differ significantly at the same laser power. As explained previously, the difference in laser absorption and scattering is one of the main causes. Another possible cause of these differences in porosity susceptibility may be the presence of a powder-depleted (PD) zone in the powder bed during the DLM process. Gusarov et al. $[19,26]$ reported that the laser beam directly interacts with the powder, as demonstrated in Figure 16. The melt pool formed around the laser beam contacts the substrate by its central part only. The lateral parts of the melt pool detach from the neighboring powder to form a round, free surface with reduced surface energy. Thus, a rearrangement densification occurs in the center of a considerably larger powder-consumed band by the action of viscous flow under capillary pressure [27]. The importance of this consolidation mechanism lies in the presence of a PD zone in the powder bed. The layered powder prior to laser irradiation may be changed significantly during powder consolidation, and the porosity generation may be directly influenced by the PD zone. The differences in motion dynamics between the large non-spherical powder and small spherical powder will change the width and irregularity of the PD zone. The PD zone is expected to increase with an increase in the non-spherical powder size. Therefore, the increased porosity densities in powders 2, 3, and 4 are assumed to be related to the increased PD zone.

The effect of defocusing distance on porosity formation was investigated using laser power of $200 \mathrm{~W}$, laser scanning speed of $110 \mathrm{~mm} / \mathrm{s}$, and line spacing of $0.06 \mathrm{~mm}$. The cross-sectional views obtained from focal distances of $-3 \mathrm{~mm},-1 \mathrm{~mm}, 0 \mathrm{~mm},+1 \mathrm{~mm}$, and $+3 \mathrm{~mm}$ are presented in Figure 17 . The plane porosity shown in Figure 18 increases as the non-spherical powder size becomes larger, regardless of the power. When the laser beam meets the focus, the plane porosity becomes low [22]. 


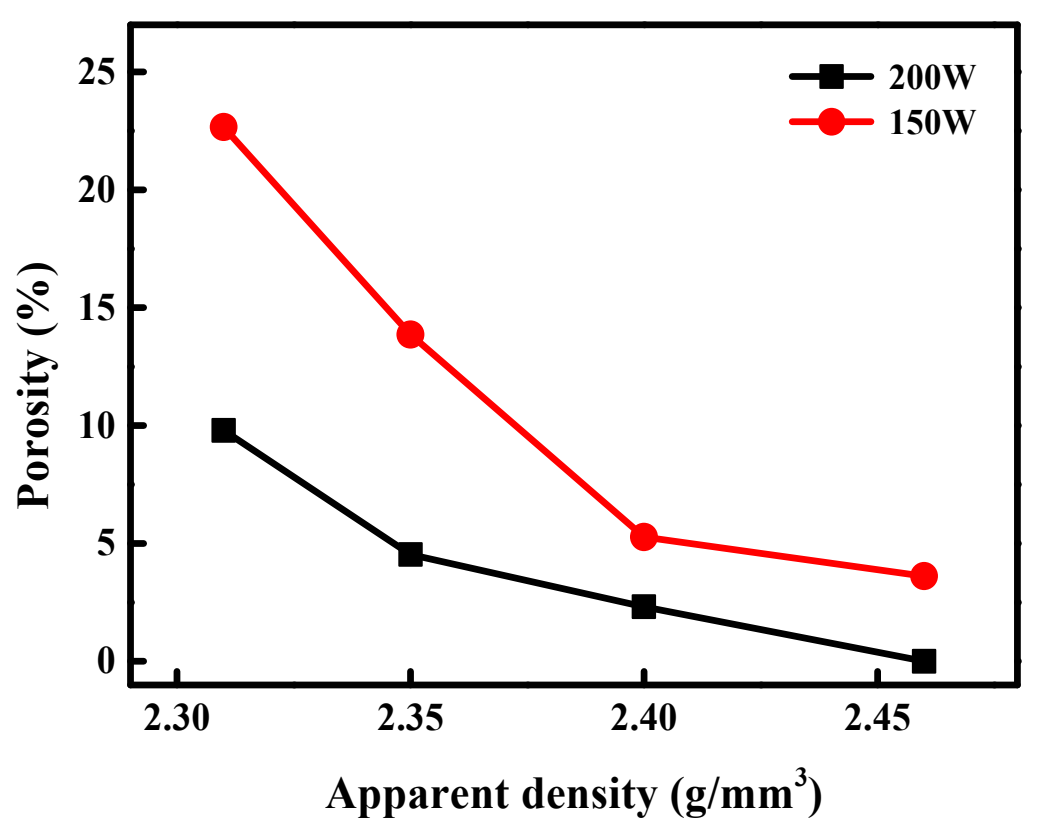

Figure 15. Relationship between the apparent density of the respective powders and the porosity of the molten layers (scan rate: $110 \mathrm{~mm} / \mathrm{s}$, line spacing $0.06 \mathrm{~mm}$ ).

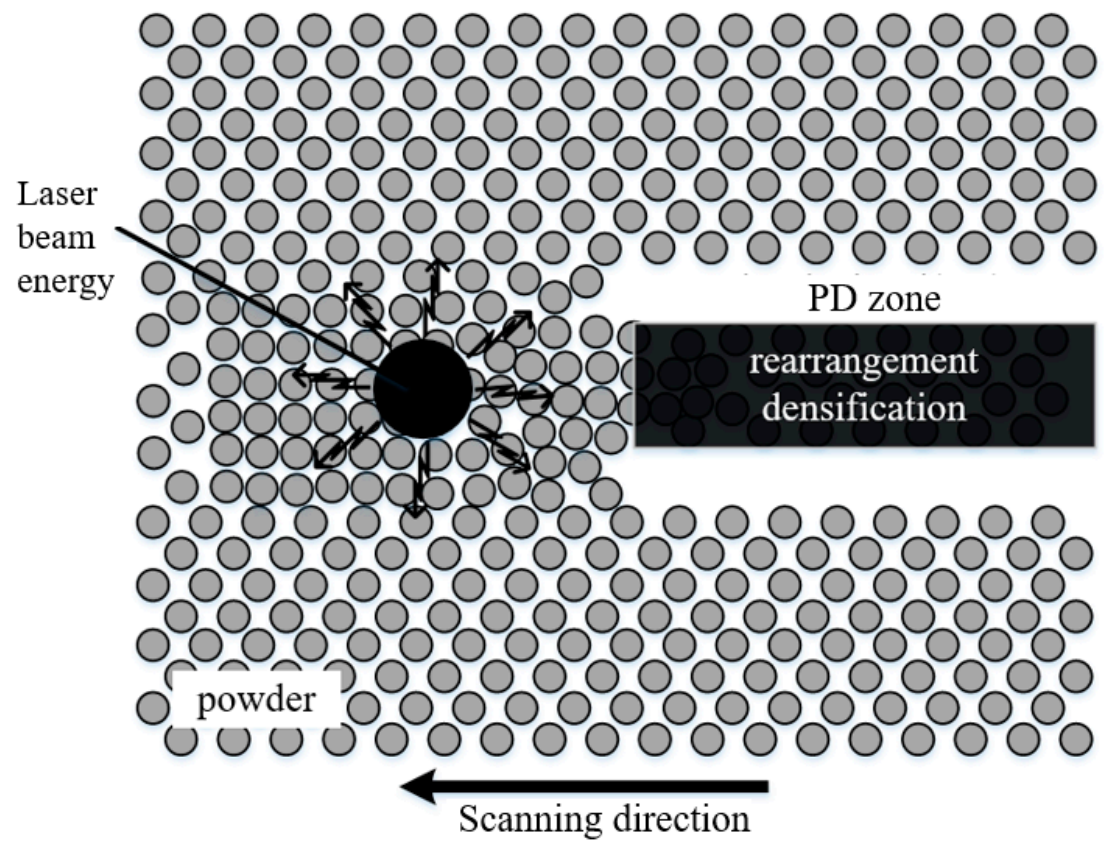

Figure 16. Schematic of rearrangement consolidation kinetics.

Figure 19 illustrates the effects of layering thickness and scan rate on plane porosity. A multi-track melting test was performed with laser power of $200 \mathrm{~W}$ and line spacing of $0.06 \mathrm{~mm}$. The porosity increases with the layering thickness and scan rate. The densification of a laser-melted layer is strongly dependent on heat concentration, and increased layering thickness and scan rate reduce the heat concentration and increase the possibility of porosity. In order to obtain a dense layer, the track being scanned must re-melt a portion of the previous layer. The layer creation is partly a result of the deposited powder and partly re-melting of the previously formed layer [28]. In the case of high powder layer thickness, a relatively small overlapped area is obtained, as illustrated in Figure 20a, where the 
porosity creation is mainly a result of insufficient melting of the deposited powder. In Figure 20b, the powder layer is significantly thinner than that in Figure 20a, and a far denser layer is obtained.

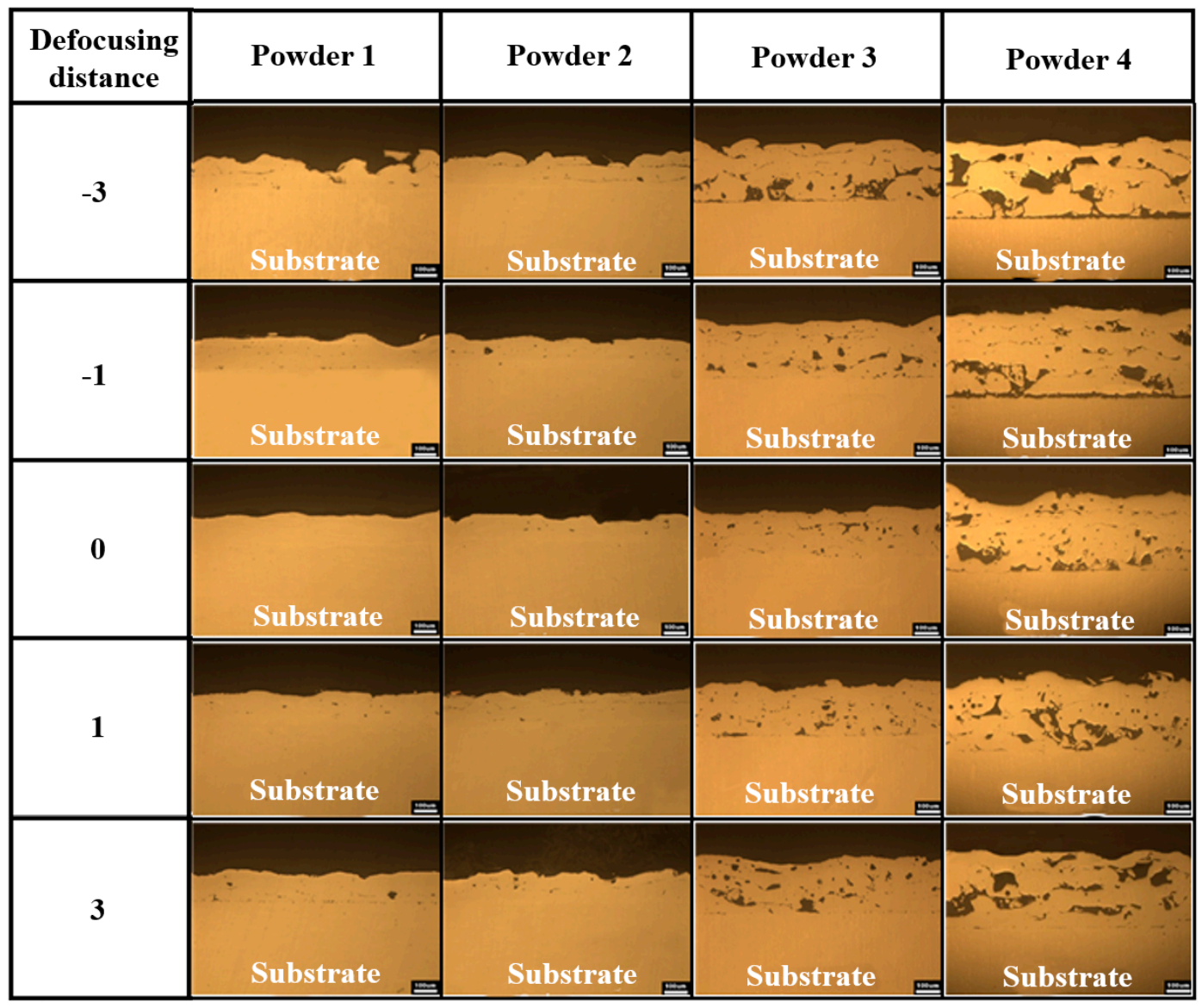

Figure 17. Porosities in deposited layers processed using different defocusing distances (mm).

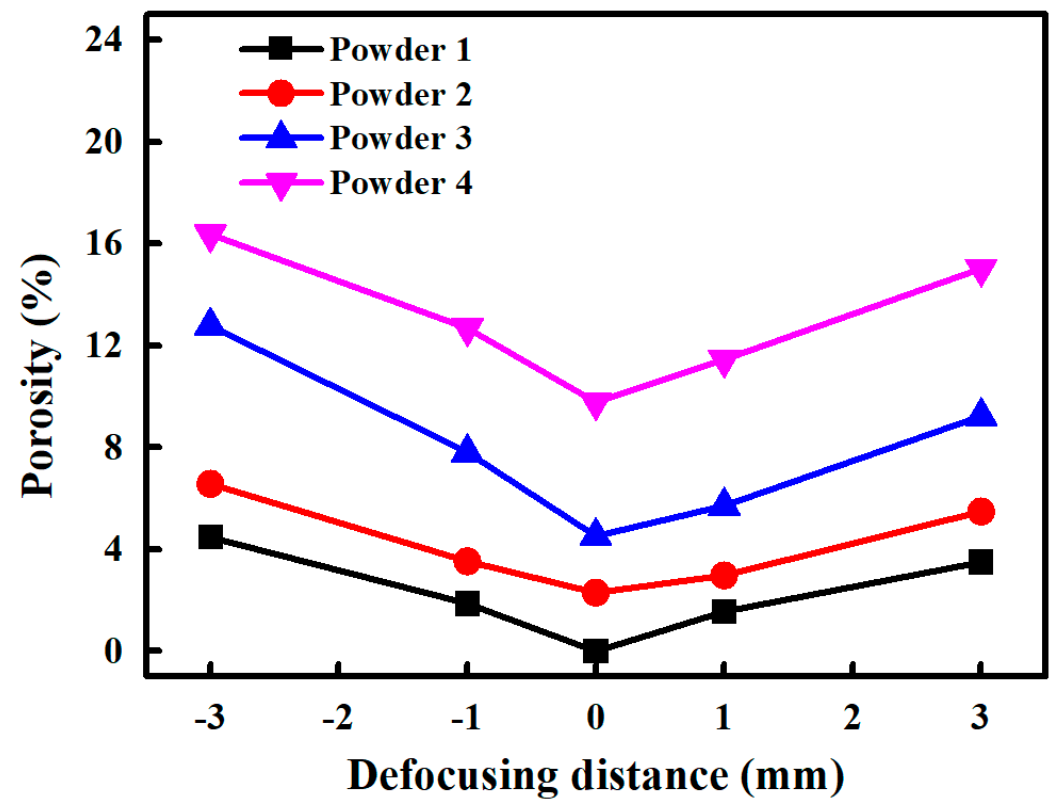

Figure 18. Effect of defocusing distance on plane porosity. 


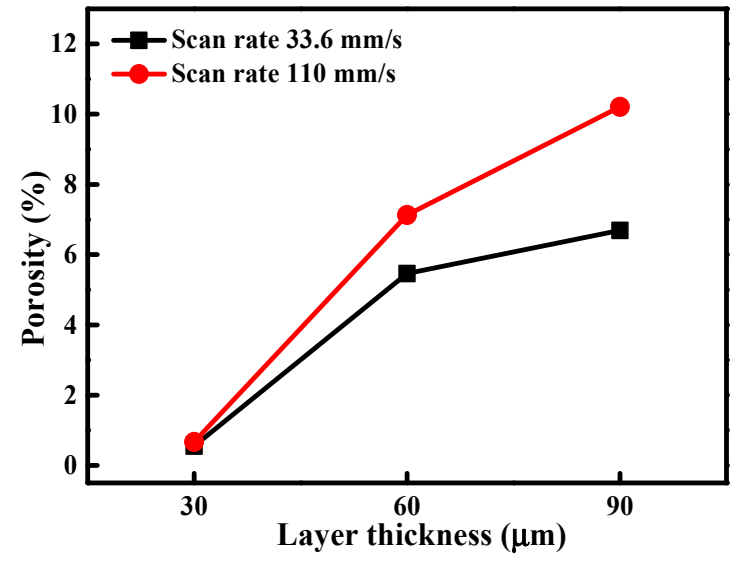

(a)

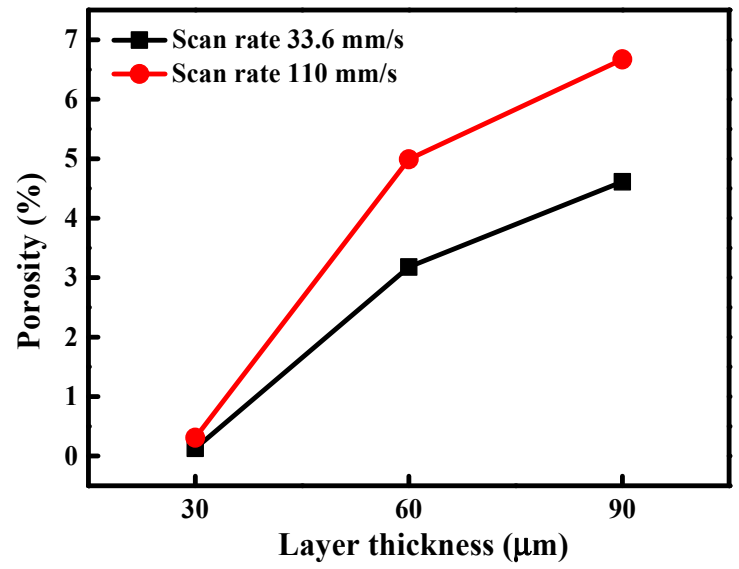

(b)

Figure 19. Effects of layering thickness on plane porosity for: (a) powder 1 and (b) powder 2.

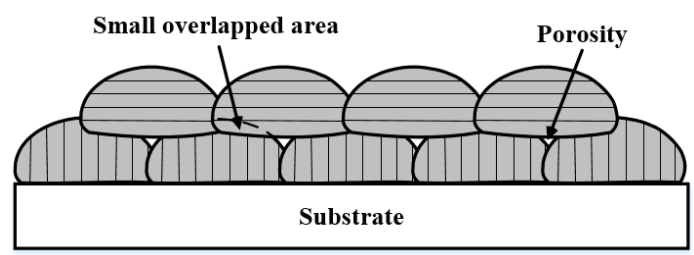

(a)

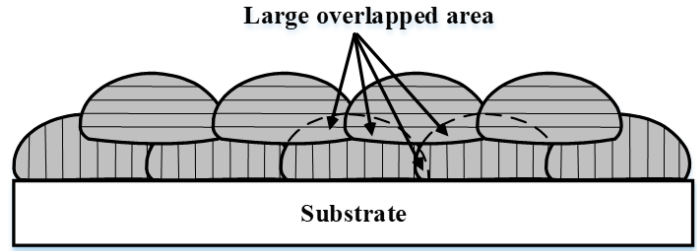

(b)

Figure 20. Schematic of two types of scanned layers: (a) small overlapping and (b) large overlapping between two adjacent layers.

Figure 21 demonstrates the effects of layering thickness and line spacing on plane porosity. A multi-track melting test was performed with a laser power of $200 \mathrm{~W}$ and scan rate of $110 \mathrm{~mm} / \mathrm{s}$. The highest porosity was achieved with a line spacing of $0.09 \mathrm{~mm}$. In the case of small line spacing, such as $0.06 \mathrm{~mm}$, the reduced empty space (and potential porosity sites) is responsible for the decreased porosity. In the case of large line spacing, such as $0.12 \mathrm{~mm}$, the empty space is readily filled during the successive laser deposition. Therefore, the variation in porosity densities with line spacing is very important for the precise control of porosity.

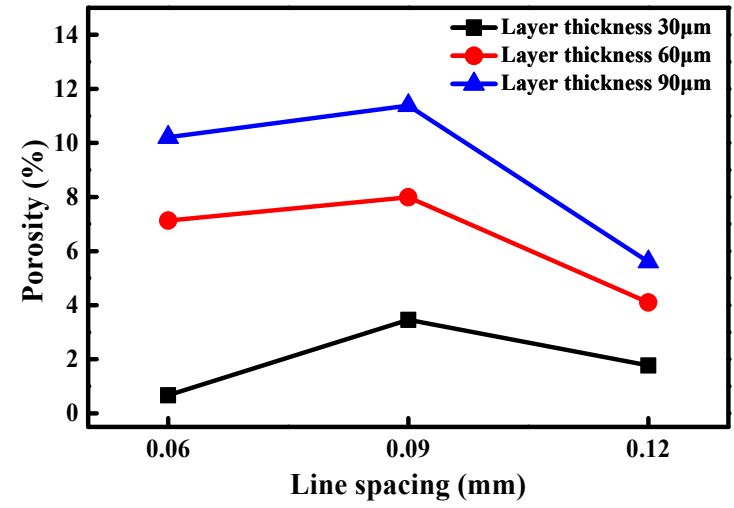

(a)

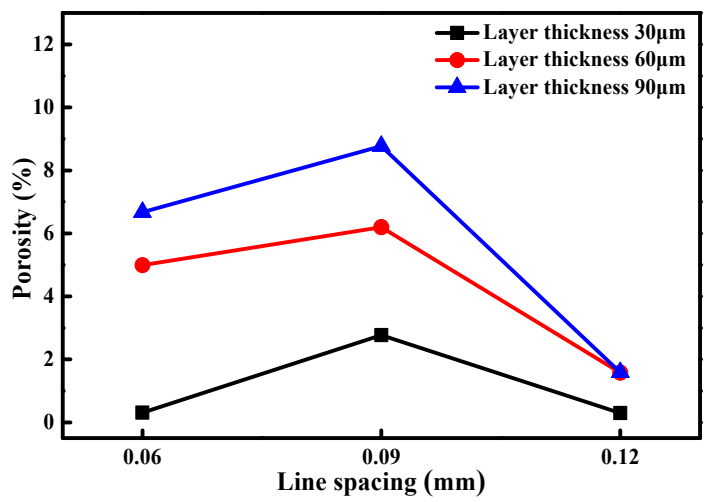

(b)

Figure 21. Effects of line spacing and layering thickness on plane porosity for: (a) powder 1 and (b) powder 2. 


\subsection{Fabrication of Part with Variable Porosities}

The porosity distribution within the respective molten layers has been measured by 3D X-Ray CT (XTH320LC, Nikon, Japan). Figure 22 shows that the porosity distributions within the respective molten layers. As shown in the figure, the porosity distributions do not show any specific directionality but appear rather isotropic and random.

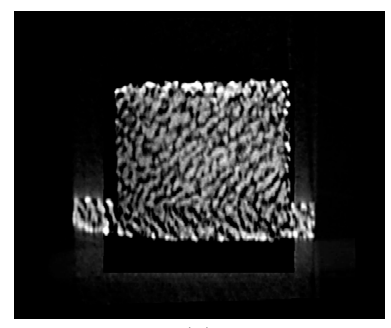

(a)

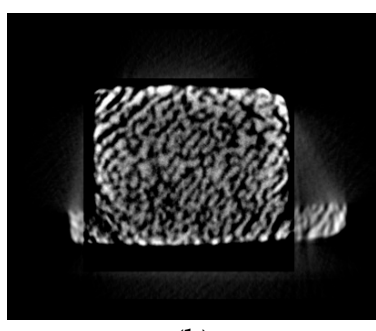

(b)

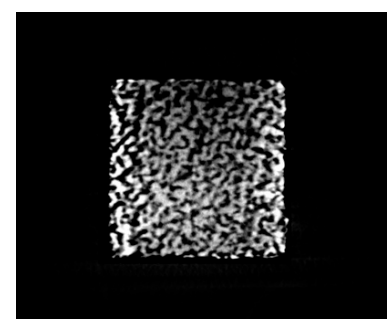

(c)

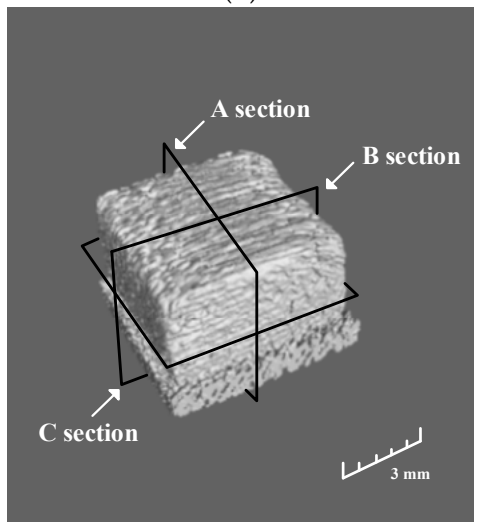

Figure 22. CT images showing porosity distribution within the respective molten layers for powder 4: (a) A section, (b) B section, and (c) C section (laser power: $150 \mathrm{~W}$, scan rate: $110 \mathrm{~mm} / \mathrm{s}$, layering; 64 passes).

A part with variable porosities was fabricated using the four test powders for validation. A DLM process was performed using a laser power of $200 \mathrm{~W}$, scan rate of $110 \mathrm{~mm} / \mathrm{s}$, and line spacing of $0.06 \mathrm{~mm}$. Figure 23 provides a cross-sectional view of the fabricated parts and variable porosity densities. As shown in the figure, parts with graded porosity densities can be successfully fabricated by a combination of process parameters and powders with customized sizes and morphologies.

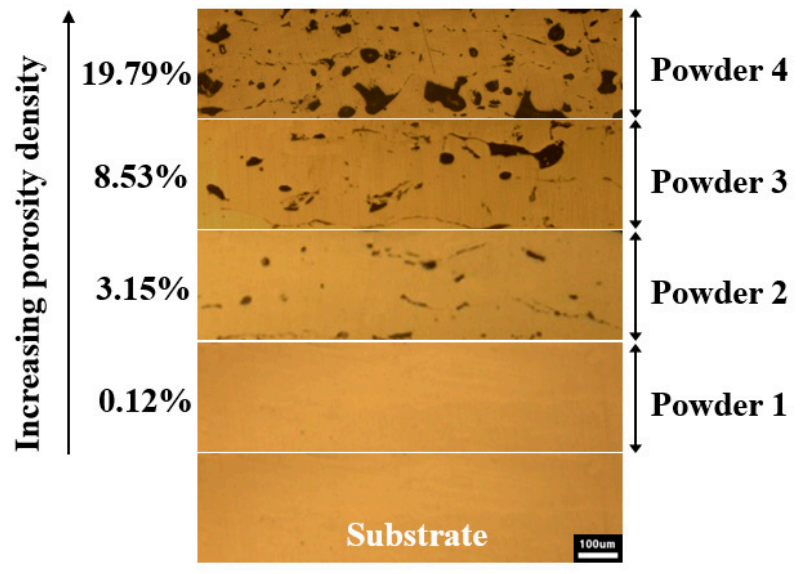

Figure 23. Parts with graded porosity densities fabricated by DLM. 


\section{Conclusions}

The effects of powder morphologies and processing parameters on porosity formation were investigated and the following conclusions were obtained:

(1) Powder morphologies and laser processing parameters are critical to porosity formation during DLM. This means that porosity during the DLM process can be actively controlled by powder morphologies and laser processing parameters.

(2) In the case of a mixed powder composed of spherical and non-spherical powders, the packing density decreases as the non-spherical powder size increases. The porosity of the laser-melted layer increases with the degree of size misfit between the non-spherical and spherical powders. Decreased laser absorption and enlargement of the PD zone as a result of decreased packing density increases the porosity during DLM.

(3) Densification of a laser-melted layer is strongly dependent on the heat concentration. Increased layering thickness and scan rate reduce the heat concentration and increase the possibility of porosity. When the powder layering thickness is large, a small overlapped area may create porosity as a result of insufficient melting of the deposited powder.

(4) The successful fabrication of functionally graded parts with variable porosity densities confirms the possibility of active control during the DLM process.

Author Contributions: All the authors have contributed equally to the conception and idea of the paper, implementing and analyzing the processing methods, evaluating and discussing the experimental results, and writing this manuscript.

Acknowledgments: This work was supported by the Institute for Information and Communications Technology Promotion (IITP) grant, funded by the Korean government (MSIP) (no. R75201600010003003, multi-material convergence $3 \mathrm{D}$ printing solution development).

Conflicts of Interest: The authors declare no conflict of interest.

\section{References}

1. Altan, T.; Lilly, B.; Yen, Y.C. Manufacturing of dies and molds. CIRP Ann. Manuf. Technol. 2001, 50, 404-422. [CrossRef]

2. Park, K.S.; VanTyne, C.J.; Moon, Y.H. Process analysis of multistage forging by using finite element method. J. Mater. Process. Technol. 2007, 187-188, 586-590. [CrossRef]

3. Kruth, J.P.; Levy, G.; Klocke, F.; Childs, T.H.C. Consolidation phenomena in laser and powder-bed layered manufacturing. CIRP Ann. 2007, 56, 730-759. [CrossRef]

4. Moon, Y.H.; Kim, D.W.; Van Tyne, C.J. Analytical model for prediction of sidewall curl during stretch-bend sheet metal forming. Int. J. Mech. Sci. 2008, 50, 666-675. [CrossRef]

5. Yi, H.K.; Kim, D.W.; VanTyne, C.J.; Moon, Y.H. Analytical prediction of springback based on residual differential strain during sheet metal bending. Proc. Inst. Mech. Eng. Part C J. Mech. Eng. Sci. 2008, 222, 117-129. [CrossRef]

6. Tang, M.; Pistorius, P.C.; Beuth, J.L. Prediction of lack-of-fusion porosity for powder bed fusion. Addit. Manuf. 2017, 14, 39-48. [CrossRef]

7. Gong, H.; Rafi, K.; Gu, H.; Starr, T.; Stucker, B. Analysis of defect generation in Ti-6Al-4V parts made using powder bed fusion additive manufacturing processes. Addit. Manuf. 2014, 1-4, 87-98. [CrossRef]

8. Qiu, C.; Adkins, N.J.E.; Attallah, M.M. Microstructure and tensile properties of selectively laser-melted and of HIPed laser-melted Ti-6Al-4V. Mater. Sci. Eng. A 2013, 578, 230-239. [CrossRef]

9. Vilaro, T.; Colin, C.; Bartout, J.D. As-fabricated and heat-treated microstructures of the Ti-6Al-4V alloy processed by selective laser melting. Metall. Mater. Trans. A 2011, 42, 3190-3199. [CrossRef]

10. Li, R.; Shi, Y.; Wang, Z.; Wang, L.; Liu, J.; Jiang, W. Densification behavior of gas and water atomized 316L stainless steel powder during selective laser melting. Appl. Surf. Sci. 2010, 256, 4350-4356. [CrossRef]

11. Khairallah, S.A.; Anderson, A.T.; Rubenchik, A.; King, W.E. Laser powder-bed fusion additive manufacturing: Physics of complex melt flow and formation mechanisms of pores, spatter, and denudation zones. Acta Mater. 2016, 108, 36-45. [CrossRef] 
12. Qiu, C.; Panwisawas, C.; Ward, M.; Basoalto, H.C.; Brooks, J.W.; Attallah, M.M. On the role of melt flow into the surface structure and porosity development during selective laser melting. Acta Mater. 2015, 96, 72-79. [CrossRef]

13. Panwisawas, C.; Qiu, C.L.; Sovani, Y.; Brooks, J.W.; Attallah, M.M.; Basoalto, H.C. On the role of thermal fluid dynamics into the evolution of porosity during selective laser melting. Scr. Mater. 2015, 105, 14-17. [CrossRef]

14. Razavi, S.M.J.; Bordonaro, G.G.; Ferro, P.; Torgersen, J.; Berto, F. Fatigue Behavior of Porous Ti-6Al-4V Made by Laser-Engineered Net Shaping. Materials 2018, 11, 284. [CrossRef] [PubMed]

15. Razavi, S.M.J.; Bordonaro, G.G.; Ferro, P.; Torgersen, J.; Berto, F. Porosity effect on tensile behavior of Ti-6Al-4V specimens produced by laser engineered net shaping technology. Proc. Inst. Mech. Eng. Part C J. Mech. Eng. Sci. 2018. [CrossRef]

16. Boley, C.D.; Khairallah, S.A.; Rubenchik, A.M. Calculation of laser absorption by metal powders in additive manufacturing. Appl. Opt. 2015, 54, 2477-2482. [CrossRef] [PubMed]

17. Zhou, J.; Zhang, Y.; Chen, J.K. Numerical simulation of laser irradiation to a randomly packed bimodal powder bed. Int. J. Heat Mass Transf. 2009, 52, 3137-3146. [CrossRef]

18. Shuming, Z.; Xianfeng, S.; Jialin, Y.; Wenhua, T.; Yingying, W. Densification behavior and mechanical properties of nanocrystalline $\mathrm{TiC}$ reinforced $316 \mathrm{~L}$ stainless steel composite parts fabricated by selective laser melting. Opt. Laser Technol. 2018, 103, 239-250.

19. Gusarov, A.V.; Yadroitsev, I.; Bertrand, P.; Smurov, I. Heat transfer modelling and stability analysis of selective laser melting. Appl. Surf. Sci. 2007, 254, 975-979. [CrossRef]

20. Jang, J.H.; Joo, B.D.; Van Tyne, C.J.; Moon, Y.H. Characterization of deposited layer fabricated by direct laser melting process. Met. Mater. Int. 2013, 19, 497-506. [CrossRef]

21. Wits, W.W.; Carmignato, S.; Zanini, F.; Vaneker, T.H.J. Porosity testing methods for the quality assessment of selective laser melted parts. CIRP Ann. 2016, 65, 201-204. [CrossRef]

22. Kasperovich, G.; Haubrich, J.; Gussone, J.; Requena, G. Correlation between porosity and processing parameters in TiAl6V4 produced by selective laser melting. Mater. Des. 2016, 105, 160-170. [CrossRef]

23. Hwang, T.W.; Woo, Y.Y.; Han, S.W.; Moon, Y.H. Functionally graded properties in directed-energy-deposition titanium parts. Opt. Laser Technol. 2018, 105, 80-88. [CrossRef]

24. Simchi, A. Direct laser sintering of metal powders: Mechanism, kinetics and microstructural features. Mater. Sci. Eng. A 2006, 428, 148-158. [CrossRef]

25. Yang, J.; Ouyang, H.; Xu, C.; Wang, Y. Top surface quality research for direct metal laser fabrication. Rapid Prototyp. J. 2012, 18, 4-15. [CrossRef]

26. Gusarov, A.V.; Smurov, I. Modeling the interaction of laser radiation with powder bed at selective laser melting. Phys. Procedia 2010, 5, 381-394. [CrossRef]

27. Cacacea, S.; Demira, A.G.; Semeraroa, Q. Densification mechanism for different types of stainless steel powders in Selective Laser Melting. Procedia CIRP 2017, 62, 475-480. [CrossRef]

28. Joo, B.D.; Jang, J.H.; Lee, J.H.; Son, Y.M.; Moon, Y.H. Selective laser melting of Fe-Ni-Cr layer on AISI H13 tool steel. Trans. Nonferr. Met. Soc. China 2009, 19, 921-924. [CrossRef]

(C) 2018 by the authors. Licensee MDPI, Basel, Switzerland. This article is an open access article distributed under the terms and conditions of the Creative Commons Attribution (CC BY) license (http://creativecommons.org/licenses/by/4.0/). 